\title{
Acute massive pulmonary embolism following pulmonary resection
}

\author{
H. M. SINGH, S. MUDBIDRI, and R. M. E. SEAL \\ Sully Hospital, nr. Penarth, Glam.
}

\begin{abstract}
Eighteen cases of acute massive and fatal pulmonary embolism following pulmonary resection are summarized. Clinical presentation is distinct in this group of patients. In one-third of the cases there was radiological evidence of major embolism several hours before the acute dramatic episode. At necropsy there seemed to be no correlation between the vascular area obstructed and the acute clinical deterioration. Longest survival occurred in those patients with $(a)$ the best pre-operative respiratory function, and $(b)$ the least operative and post-operative complications.
\end{abstract}

Acute massive pulmonary embolism following any kind of surgery carries a high mortality. Despite the availability of pulmonary angiography and extracorporeal circulation, the overall mortality remains considerable (Leading article, Brit. med. J., 1968 ; Editorial, Dis. Chest, 1969 ; Sautter, Emanuel, and Wenzel, 1967). It might be expected that the problem is particularly sinister when it occurs following pulmonary resection.

We present an account of 18 cases of pulmonary resection complicated by acute massive and fatal pulmonary embolism in the belief that these cases behave differently clinically and raise problems in diagnosis and management which are unique. Moreover, although it is well recognized that massive pulmonary embolism may be preceded by evidence of minor embolic episodes, it is not generally appreciated that there are in some instances definite radiological signs of occlusion of major vessels even before the acute clinical episode.

\section{METHODS AND MATERIALS}

Between 1959 and 1968 at Sully Hospital 18 deaths were confirmed to be due to acute massive pulmonary embolism at necropsy in patients who had had some form of pulmonary resection. Excluded from this series were all those patients in whom pulmonary embolism may have contributed to death in association with other causes. In almost all cases it was usual to find the embolus occluding one of the main pulmonary vessels, propagating into one or more of its branches.

CLINICAL MATERIAL The ages of our patients ranged between 51 and 70 years. The mean age was 62 years. Men predominated in the series. There were only three women in the group. Pulmonary resection in all cases was for bronchial carcinoma. Ten patients had a lobectomy carried out, while eight had needed a pneumonectomy. Pre-operative pulmonary function tests showed the following results:

14 patients had moderate to severe obstructive airways disease ;

7 patients had restrictive airways disease ;

2 patients had normal pulmonary function.

Mean values for the group were as follows:

$\begin{array}{lcc} & & \text { Mean deviation } \\ \mathrm{FEV}_{1} & 1.91 . & \pm 0.61 . \\ \mathrm{VC} & 2.81 . & \pm 0.81 . \\ \mathrm{FEV}_{1} / \mathrm{VC} & 68 \% & \pm 18 \%\end{array}$

SEVERITY OF SURGICAL TRAUMA Tables I, II, and III depict the duration of surgical operation, blood requirements and untoward incidents during the surgical procedure, respectively.

T A B L E I

DURATION OF SURGICAL OPERATION

\begin{tabular}{ll|c|l}
\hline \multicolumn{2}{c|}{ Duration } & No. of Patients & \\
\cline { 1 - 2 } Less than $2 \mathrm{hr}$. & $\ldots$ & 6 & Average time \\
$2-3 \mathrm{hr}$. & 9 & in 18 cases: \\
More than $3 \mathrm{hr}$. & $\cdots$ & 3 & $2 \mathrm{hr} .55 \mathrm{~min}$. \\
\hline
\end{tabular}

T A B L E I I

BLOOD REQUIREMENTS

\begin{tabular}{|c|c|c|c|}
\hline & & No. of Patients & \\
\hline $\begin{array}{l}\text { Less than } 1 \text { litre } \\
1-2 \text { litres } \ldots \\
\text { Over } 2 \text { litres }\end{array}$ & $\begin{array}{l}\cdots \\
\cdots\end{array}$ & $\begin{array}{l}5 \\
6 \\
7\end{array}$ & $\begin{array}{l}\text { Average requirements } \\
\text { in } 18 \text { cases: } \\
2 \cdot 1 \text { litres }\end{array}$ \\
\hline
\end{tabular}


T A B L E I I I

UNTOWARD INCIDENTS DURING SURGICAL PROCEDURE

\begin{tabular}{|c|c|c|}
\hline & & No. of Patients \\
\hline $\begin{array}{l}\text { Haemorrhage (blood loss of over } 2 \text { litres) } \\
\text { Cardiac arrest } \ldots \\
\text { Tachycardias and ectopic rhythms } \\
\text { Dislocation of the heart } \ldots\end{array}$ & $\begin{array}{l}\cdots \\
\cdots \\
\cdots\end{array}$ & $\begin{array}{l}7 \\
1 \\
2 \\
1\end{array}$ \\
\hline
\end{tabular}

The corresponding figures in 20 successive cases of similar age group and sex incidence, undergoing major resections, were as follows:

Mean duration of surgical operation-2 hr. $5 \mathrm{~min}$.

Mean blood requirements-1.4 litres.

POST-OPERATIVE COURSE Table IV enumerates some of the post-operative complications encountered in the 18 cases studied

T A B LE I V POST-OPERATIVE COMPLICATIONS

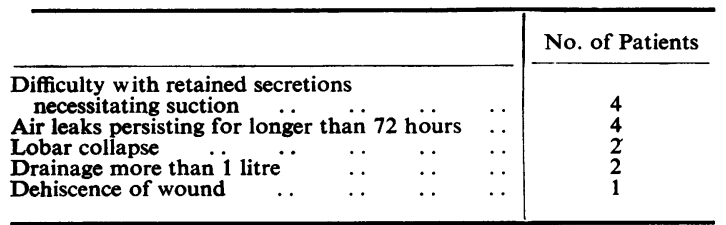

Charts were scrutinized for evidence of deep venous thrombosis, haemoptysis and rise in temperature, pulse rate and respiration before the acute episode. The time intervals between the surgical operation and (a) the development of the acute incident, and $(b)$ the final collapse were noted. Mode of death and clinical presentation during the acute episode were studied. A retrospective evaluation of the chest radiographs in all these patients was carried out. In particular, the size of the pulmonary artery at the level of the anterior end of the fourth costal cartilage, vascular markings at the periphery, the presence of the 'cut-off' sign and any evidence of collapse, consolidation and effusion were noted. These radiographs were compared with those of 20 successive uncomplicated patients undergoing major resections for carcinoma of lung in order to exclude misinterpretation of changes due solely to the operative procedure.

\section{RESULTS}

Table $\mathrm{V}$ depicts the occurrence of the acute episode from the time of the surgical procedure.

\section{T A B L E V}

OCCURRENCE OF ACUTE EPISODE

\begin{tabular}{|c|c|c|}
\hline & & No. of Patients \\
\hline $\begin{array}{l}\text { Within } 3 \text { days of operation } \\
\text { Between 4th and } 7 \text { th post-operative day } \\
\text { During 2nd week post-operatively } \\
\text { During the 3rd week post-operatively } \\
\text { Beyond the 3rd week }\end{array}$ & $\begin{array}{ll}\cdots & \cdots \\
\cdots & \cdots \\
\cdots & \cdots\end{array}$ & $\begin{array}{l}3 \\
3 \\
6 \\
5 \\
1\end{array}$ \\
\hline
\end{tabular}

Death ensued within minutes of the acute epi- $\vec{\Rightarrow}$ sode in 12 of the patients; a further four died $\stackrel{5}{+}$ within two hours of the episode. Only two patients survived for periods ranging between two and four hours.

In six patients the acute episode was precipi- $\stackrel{\overparen{D}}{\varrho}$

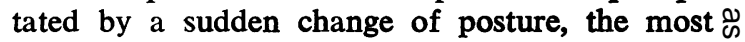
commoniy described in the series being that the $\vec{A}$ patient was sitting up from the chair to get into ? bed when he suddenly became breathless. Clinical $\vec{\omega}$ deep vein thrombosis was recognized in one case ; none had haemoptysis preceding the dramatic $\vec{x}$ episode.

Table VI depicts the clinical picture. Breathless- of ness with central cyanosis was present in all. $\omega$ Sweating and blanching of the skin on pressure 0 were common occurrences. High central venous 윽 pressure with collapsed peripheral veins and hypo- tension were fairly characteristic features.

Only six electrocardiograms were obtained during the acute episode ; the changes were those $\overrightarrow{0}$

\section{T A B L E V I \\ CLINICAL PICTURE}

\begin{tabular}{|c|c|c|c|c|}
\hline & & & & No. of Patients \\
\hline 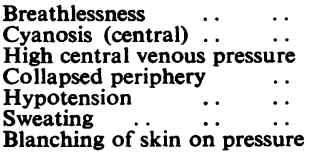 & $\begin{array}{l}\cdots \\
\cdots \\
\cdots \\
\cdots \\
\ldots \\
\cdots\end{array}$ & $\begin{array}{l}\ldots \\
\ldots \\
\ldots \\
\ldots \\
\ldots \\
\ldots\end{array}$ & $\begin{array}{l}\cdots \\
\cdots \\
\cdots \\
\cdots \\
\cdots\end{array}$ & $\begin{array}{l}18 \\
18 \\
15 \\
15 \\
15 \\
14 \\
14\end{array}$ \\
\hline
\end{tabular}

of right ventricular strain in three but were nonspecific (Sabiston and Wagner, 1965).

Table VII summarizes the findings in the immediate pre-embolus radiological plates.

T A B L E V I I

RADIOLOGICAL FINDINGS

\begin{tabular}{|c|c|c|c|c|}
\hline & & & & No. of Patients \\
\hline \multicolumn{5}{|c|}{$\begin{array}{l}\text { Dilatation of pulmonary artery of more than } \\
5 \mathrm{~mm} \text {. and mean increase in width of }\end{array}$} \\
\hline ‘ $10.5 \mathrm{~mm}$. & & .. & & 12 \\
\hline \multirow{2}{*}{\multicolumn{5}{|c|}{$\begin{array}{l}\text { Diminution in vascular markings at periphery } \\
\text { Associated localized signs: }\end{array}$}} \\
\hline & & & & \\
\hline Effusion & .. $\quad$. & .. & $\ldots$ & 1 \\
\hline Collapse. & .. & .. & .. & 1 \\
\hline Consolidation & .. & . & .. & 1 \\
\hline
\end{tabular}

A corresponding increase in the pulmonary artery following the uncomplicated cases of lobectomy and pneumonectomy averaged $6 \mathrm{~mm}$. in 20 consecutive cases. Immediately after the procedure the lung fields in this group of patients were plethoric and took an average of two to 


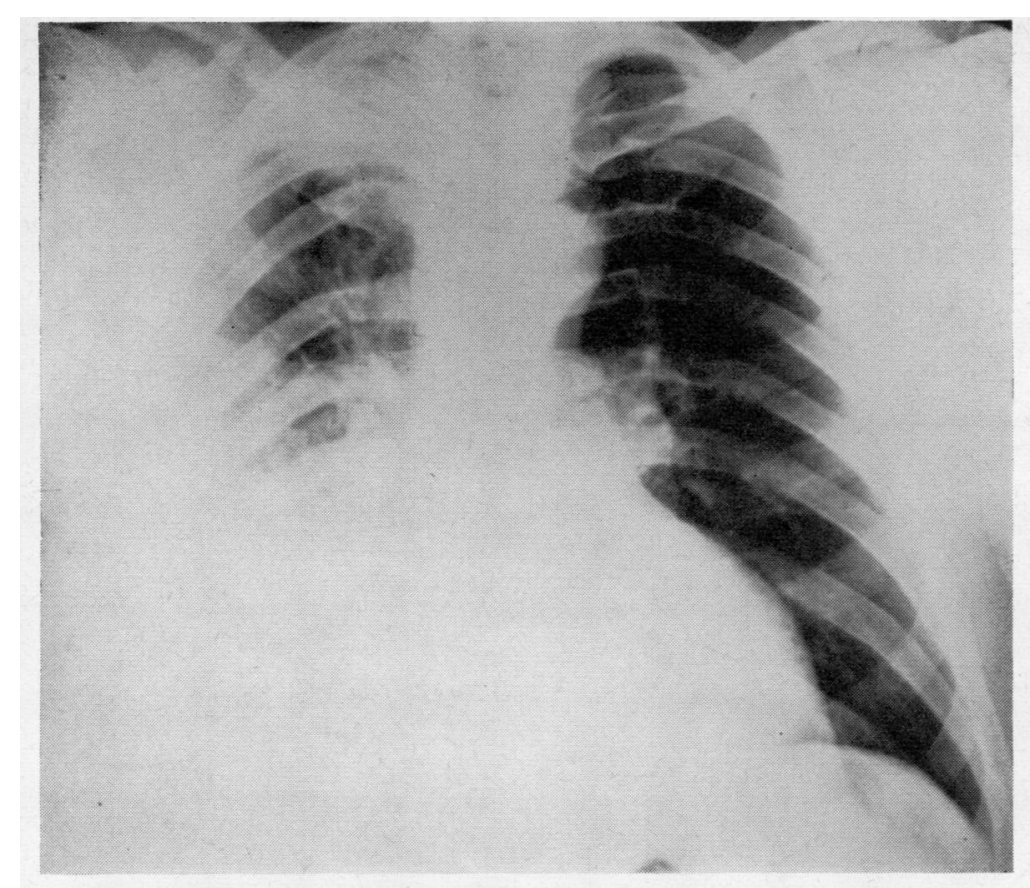

(a)

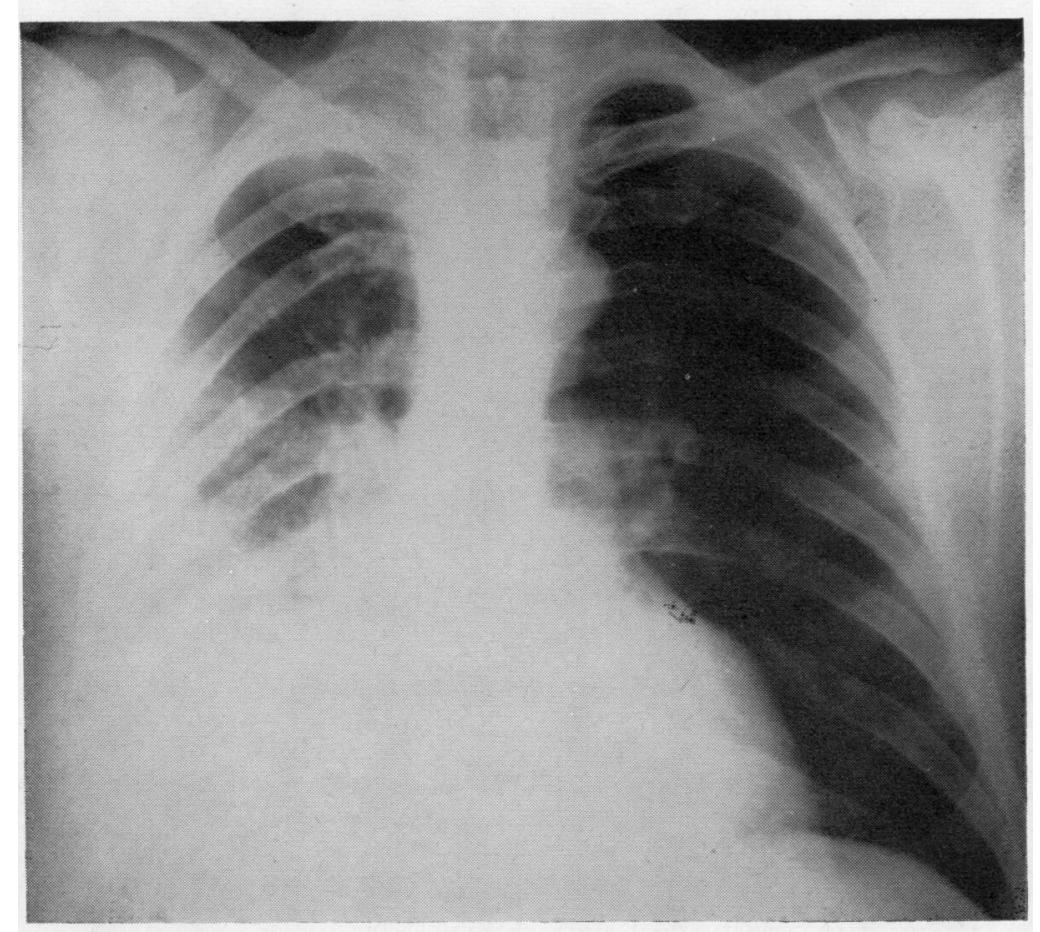

(b)

FIG. 1. Right lower lobectomy. (a) After right lower lobectomy; (b) 6 hours before acute episode showing (1) dilated left pulmonary artery, (2) pale periphery on the left, and (3) 'cut-off'. 


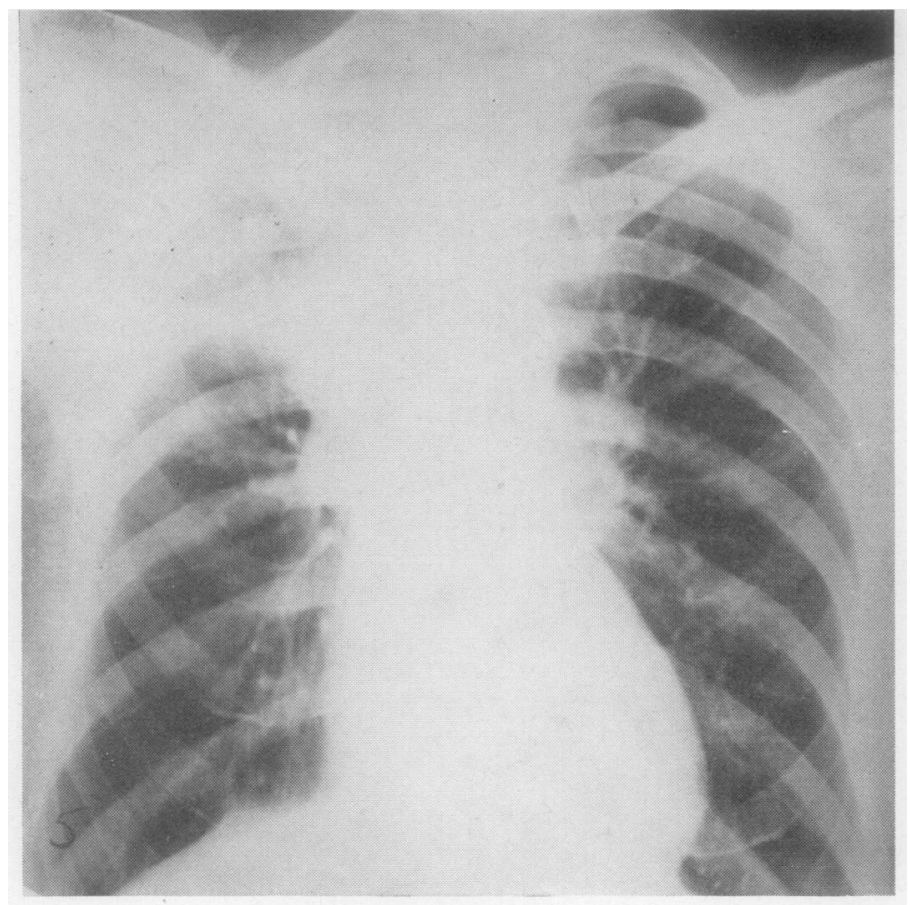

(a)

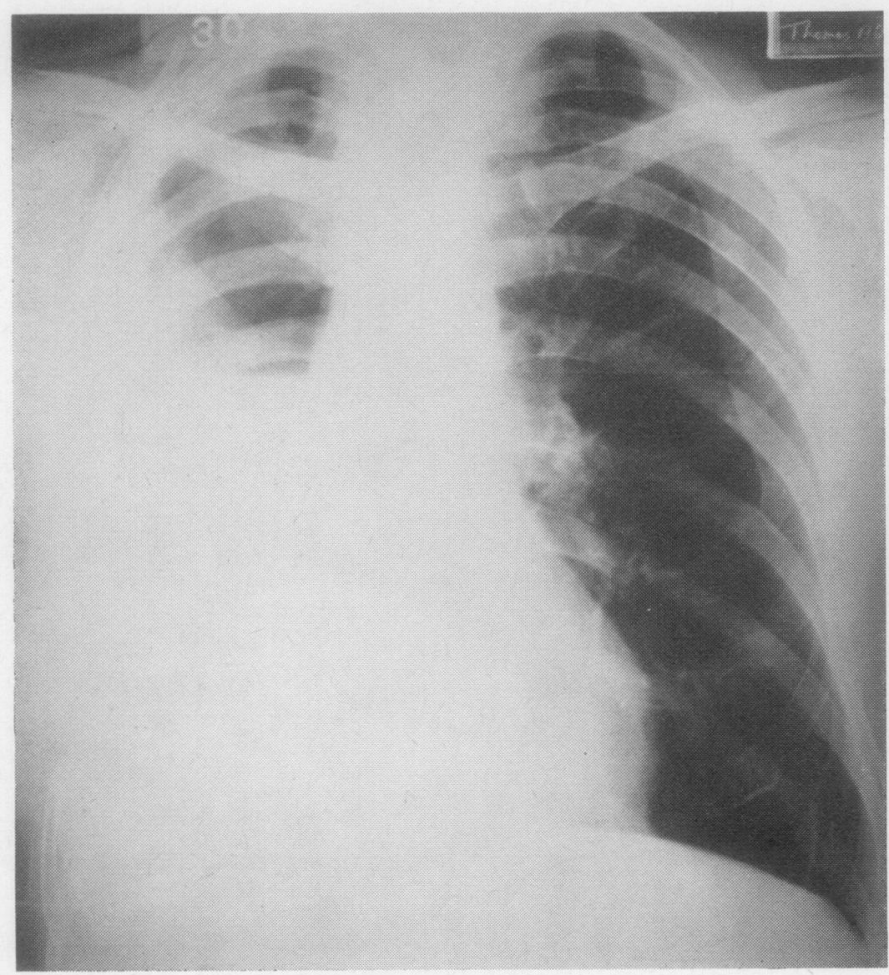

(b)

FIG. 2. Right pneumonectomy. (a) Pre-operative radiograph; (b) $4 \frac{1}{2}$ hours before acute episode. 'Cut-off' sign and pale periphery on left. 


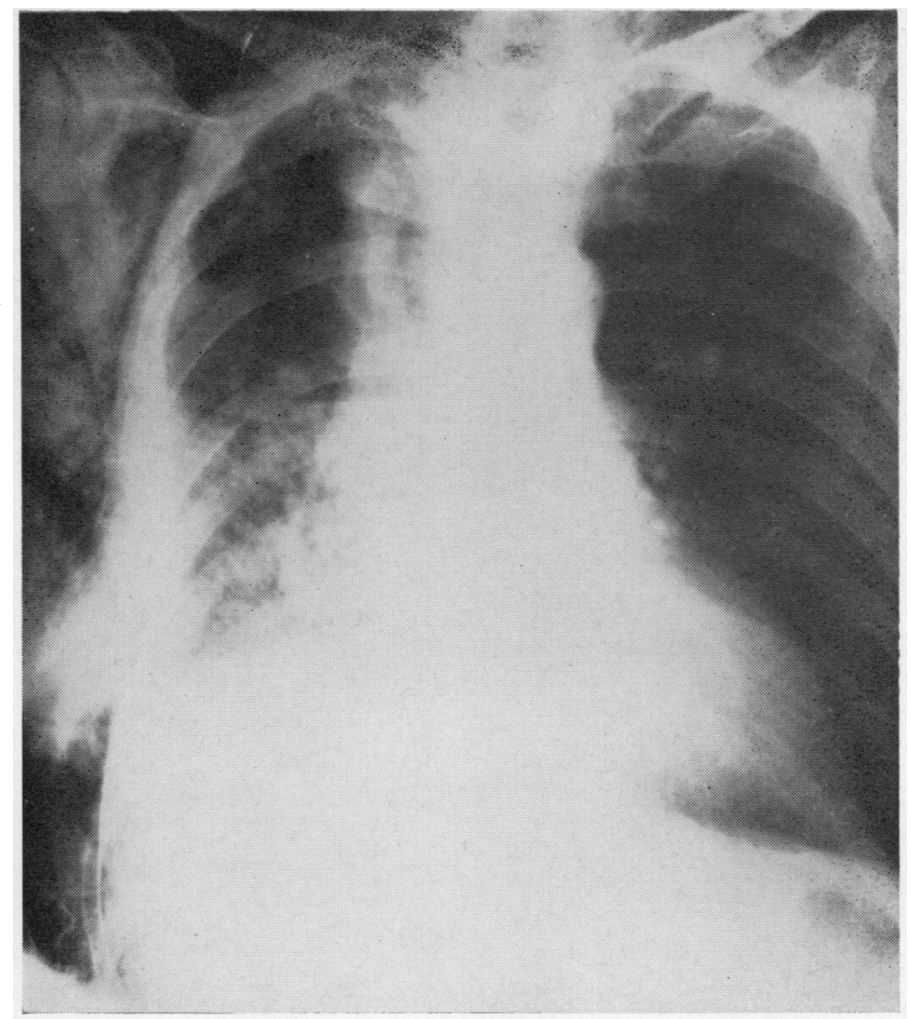

(b)

FIG. 3. Lobectomy. (a) Immediately after right lower lobectomy; (b) 2 hours before acute episode. Dilatation of left pulmonary artery and 'cut-off' sign.

(a)

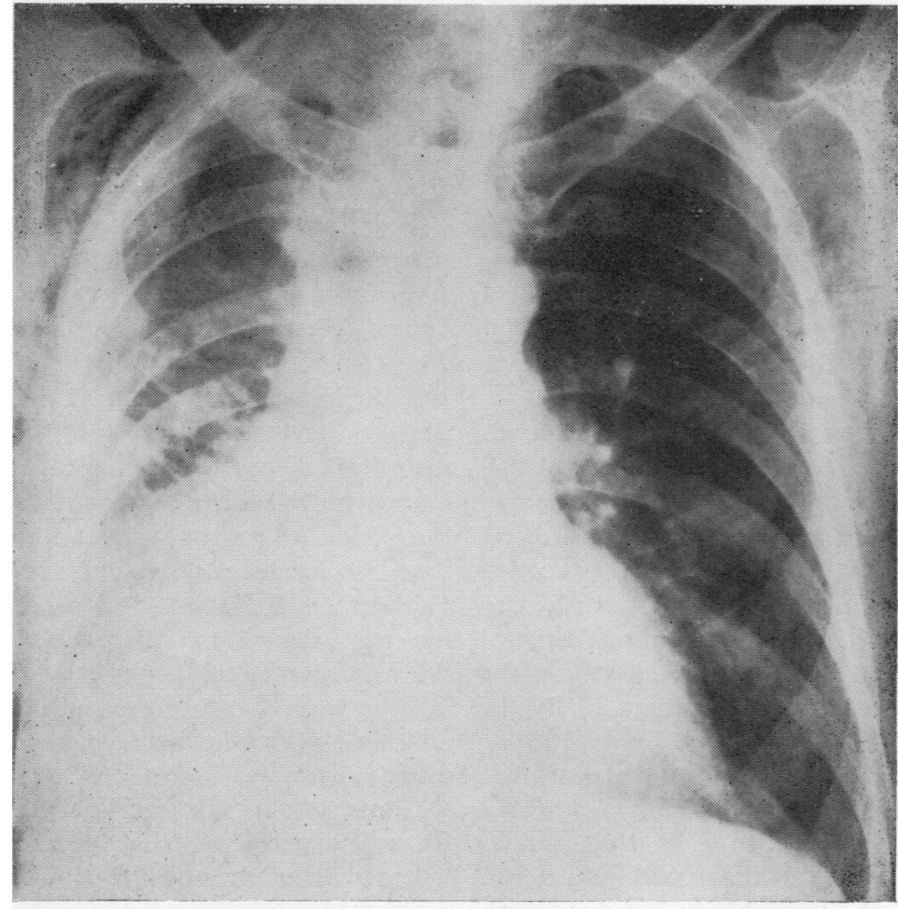




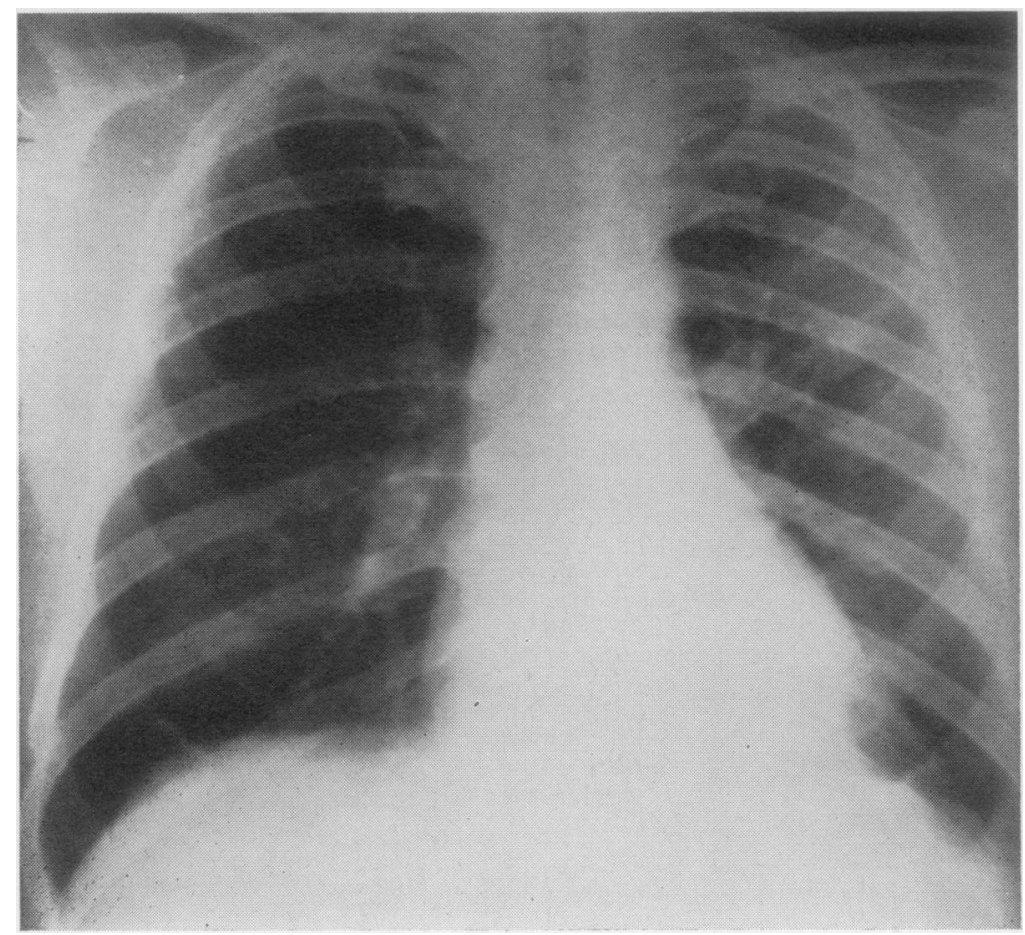

FIG. 4. Asymptomatic. Died suddenly before bronchoscopy for investigation of? obstructive emphysema on the right. Necropsy showed massive pulmonary embolus.

three days to clear. In none was the 'cut-off' sign present, nor was there a diminution of vascular markings at the periphery.

\section{DISCUSSION}

The clinical picture in our patients has almost always been of acute respiratory and circulatory embarrassment, resulting in death in a matter of minutes; only two patients survived for more than two hours. Pulmonary angiography preceding embolectomy cou'd be contemplated only in these two cases. Gorham, in 1961 in a retrospective study of 100 proved and unselected cases of massive pulmonary embolism, noted that 22 lived up to two hours and 34 up to 14 days. Thus more than half the cases survived long enough to allow embolectomy. The obvious explanation for this marked difference in survival time is that after pulmonary resection the vascular bed, already considerably diminished, withstands obstruction poorly, leading to an early fatal end.
Serial radiography, despite its limitations, has proved invaluable in the diagnosis of acute massive pulmonary embolism (Soloff and Rodman, 1967; Barraclough and Braimbridge, 1967 ; Fleischner, 1962; Torrance, 1963; Follath, Burkart, and Fridrich, 1968). What has impressed us even more has been the fact that the radiological signs of acute massive pulmonary embolism have been present in about one-third of the cases in radiographs taken several hours before the acute clinical episode. Fleischner (1962), Follath et al. (1968), and others have emphasized the importance of dilated pulmonary arteries in the antero-posterior view. While not refuting this in any way, we have placed only a limited value on this sign alone because such dilatation of pulmonary arteries frequently occurs after major resections uncomplicated by pulmonary embolism. Its association with a 'pale' periphery and the 'cut-off' sign has been considerably more significant (Soloff and Rodman, 1967 ; Barraclough and Braimbridge, 1967 ; Fleischner, 1962 ; Tor- 
rance, 1963). In none of the comparative group of uncomplicated cases have these signs been present. The appearance of these radiological signs before the acute episode may mean the presence of a major embolus that fails to obtrude on the clinical picture.

As we have not yet met the 'cut-off' sign, other than in our patients who proceeded to the picture of massive embolism within 2 to 18 hours, it seems that the appearance of this sign in the postoperative period should occasion urgent action, possibly leading to embolectomy. However, before adopting such an active policy on the evidence of a small retrospective series, even with matched controls, it may be considered desirable to evaluate the prognostic significance of this sign in more detail on a larger series.

Post-mortem assessment of the amount of circulation obstructed is somewhat arbitrary and inaccurate in that frequently many small branches previously occluded are overlooked, and on the other hand there may be surprising flow around a thrombus that apparently comp'etely occludes the lumen. In the two patients who survived longest there was no evidence at necropsy that the embolic occlusion was any less severe than in the immediately fatal cases. The main factor contributing to the longer survival in these cases appears to be that $(a)$ they had the best pre-operative pulmonary functions in the series, $(b)$ they both had only a right upper lobectomy, and $(c)$ operative trauma, as judged by our criteria, had been minimal. This agrees in essence with the work of McIntyre and Sasahara (1970), who believe that the response to any given episode of embolic obstruction depends primarily on the state of the cardiopulmonary system prior to embolization and only secondarily on the magnitude of embolic obstruction.

The operative trauma in this group of patients, as judged by our criteria, has been significantly greater than in the 'control' group, and this difference in the groups is also true of the postoperative period. Many factors are known to favour deep venous thrombosis, and it appears that such factors as the amount of blood transfused, the length of operation and the more common post-operative complications must also play a part. Venous thrombosis being commoner than clinical pulmonary embolism, it is likely that such factors should influence the venous thrombotic process rather than the tendency for these thrombi to become detached. The fact that the initial lung lesion has been a bronchial carcinoma with its known increased tendency to hypercoagulability, a case could be made of an early and effective anticoagulation in those patients undergoing pulmonary resection, where either the operative or the post-operative period has been particularly difficult.

\section{REFERENCES}

Barraclough, M. A., and Braimbridge, M. V. (1967). Massive pulmonary embolism. Brit. med. J., 1, 217.

Editorial (1969). Pulmonary embolectomy [signed Sasahara, A. A., Wheeler, H. B., McIntyre, K. M., and Criss, A. J.] Dis. Chest, 56, 89.

Fleischner, F. G. (1962). Pulmonary embolism. Clin. Radiol., 13, 169.

Follath, F., Burkart, F., and Fridrich, R. (1968). Zur Beurteilung des Thoraxbildes bei akuter Lungenembolie. Schweiz. med. Wschr., 98, 1589.

Gorham, L. W. (1961). A study of pulmonary embolism. Arch. intern. Med., 108, 8.

Leading article (1968). Management of pulmonary embolism. Brit. med. J., 4, 133.

McIntyre, K. M., and Sasahara, A. A. Determinants of the haemodynamic response to pulmonary embolism. Submitted for publication.

Sabiston, David C., Jr., and Wagner, H. N., Jr. (1965). The pathophysiology of pulmonary embolism: relationships to accurate diagnosis and choice of therapy. J. thorac. cardiovasc. Surg., 50, 339.

Sautter, R. D., Emanuel, D. A., and Wenzel, F. J. (1967). Treatment of acute massive pulmonary embolism-medical or surgical. Ann. thorac. Surg., 95, 4.

Soloff, L. A., and Rodman, T. (1967). Acute pulmonary embolism II. Clinical. Amer. Heart J., 74, 829.

Torrance, D. J. (1963). The Chest Film in Massive Pulmonary Embolism. Thomas, Springfield, Ill. 